\title{
MEASUREMENTS OF FRICTION COEFFICIENTS OF SNOW BLOCKS
}

\author{
by
}

\author{
G. Casassa, H. Narita, and N. Maeno
}

(The Institute of Low Temperature Science, Hokkaido University, Sapporo 060, Japan)

\section{ABSTRACT}

Snow blocks were slid down natural snow slopes and filmed with a video camera. Friction coefficients were calculated from time-distance curves and the equation of motion. Dry-friction coefficients ranged from 0.57 to 0.84 , and could be separated into Coulomb friction and a friction component proportional to the contact area of the blocks (adhesion). These values are greater than the values usually used in avalanche dynamics, but are consistent with previous coefficients obtained for snow blocks sliding over snow.

When uniform ploughing occurred and a shear layer developed along the track the apparent friction coefficients increased with velocity, and could be modelled by considering the kinematic viscosity of the snow. The values of kinematic viscosity ranged from $10^{-3}$ to $10^{-4} \mathrm{~m}^{2} / \mathrm{s}$ and agreed well with those values obtained by other researchers.

\section{INTRODUCTION}

Most of the studies on snow friction have been done on friction between snow and other materials (Lang and Dent, 1982), in particular in relation to ski and sled sliding. In contrast, friction between two snow bodies has received little attention, even though it is of basic importance in avalanche dynamics. In fact, the frictional force acting between a moving snow avalanche and its bed has been recognized as one of the main factors influencing the motion of an avalanche. In the present study snow-to-snow friction was estimated from the measurement of the sliding velocity of snow blocks on a natural snow slope.

\section{FRICTION RESISTANCE}

The friction resistance force acting on a moving avalanche has traditionally been expressed as a truncated power series of its velocity $v$ (Salm, 1966), according to the equation

$$
F=A+B v+C v^{2}
$$

where $A$ is the dry friction force, $B$ is the viscous friction coefficient, and $C$ is the turbulent friction coefficient. Dry friction, as often used in wear and tribology science, is the contact friction between dry solids in the absence of a lubricant. Dry friction includes Coulomb friction and adhesion; the former is friction proportional to the normal force, and the latter is a force proportional to the contact area, so that

$$
A=\mu_{\mathrm{c}} N+a g S
$$

where $\mu_{\mathrm{c}}$ is the Coulomb friction coefficient, $N$ is the normal force acting on the surface, $a$ is the adhesion coefficient (mass per unit area), $g$ is the acceleration due to gravity, and $S$ is the surface area. This is equivalent to the Mohr-Coulomb definition of shear strength of materials

$$
\tau=H+\sigma \tan (\phi)
$$

where $\tau$ is the shear strength, $H$ is the cohesion strength, and $\phi$ the angle of internal friction.

If snow is considered to behave as a fluid with a certain kinematic viscosity, $v$, its viscous coefficient, can $B$, be expressed as

$$
B=\frac{\rho S v}{\delta} N
$$

where $\delta$ is the shear layer thickness and $\rho$ the snow density.

The turbulent resistance, $C v^{2}$, includes air drag and ploughing effect as well as the turbulent internal friction of the avalanche, but in fact both compression and shearing of snow on the track also take place, and for this a square-of-velocity model may be inappropriate.

\section{PREVIOUS WORK}

Inaho (1941) was the first to publish snow-to-snow friction data. He slid blocks of granular snow over slopes covered with granular snow at temperatures near to $0^{\circ} \mathrm{C}$ and at velocities of up to $4 \mathrm{~m} / \mathrm{s}$. Inaho considered both Coulomb and adhesion friction forces, as represented in the equation of motion

$$
m \frac{\mathrm{d} v}{\mathrm{~d} t}=m g \sin \alpha-\left(\mu_{\mathrm{c}} m g \cos \alpha+a g S\right)
$$

where $m$ is the block mass, $v$ is the velocity, $t$ is the time, and $\alpha$ is the slope angle.

By combining both Coulomb forces and adhesion effects into one total dry friction coefficient, $\mu$, the equation below can be applied

$$
\mu=\mu_{\mathrm{c}}+\frac{a S}{m \cos \alpha}
$$

for which values of $\mu$ ranging from 0.45 to 0.64 have been obtained. Inaho presented Coulomb coefficients ranging in value from 0.42 to 0.62 , and his adhesion coefficients varied from 1.3 to $8.7 \mathrm{~kg} / \mathrm{m}^{2}$, with a mean of $5.1 \mathrm{~kg} / \mathrm{m}^{2}$.

Bucher and Roch (1946) pulled blocks of wet granular snow over a flat surface of wet granular snow at velocities in the range $0.2-2.4 \mathrm{~m} / \mathrm{s}$, and obtained friction coefficients ranging from 0.23 to 0.85 . Their data also gave a viscous coefficient per unit area of $475 \mathrm{~N} \mathrm{~s} / \mathrm{m}^{3}$. For movement at constant speeds this data is in agreement with the Mohr-Coulomb theory. Adhesion coefficients of 27 and $157 \mathrm{~kg} / \mathrm{m}^{2}$ were obtained for these experiments, which are larger values than Inaho reported. These high values can be explained by the slow friction speeds involved, in fact the Mohr-Coulomb criteria have traditionally been applied in soil mechanics at static or low deformation rates.

Japan National Railways (1961) slid snow blocks down slopes of either granular or compacted snow, sometimes covered with new snow, at speeds up to a maximum of about $20 \mathrm{~m} / \mathrm{s}$. Friction coefficients obtained as a result of such experiments ranged from 0.55 to 1.00 , the highest values including ploughing effect, with mean dry friction of 
0.71 for compact snow $\left(\rho>350 \mathrm{~kg} / \mathrm{m}^{3}\right)$ and 0.69 for granular snow $\left(\rho>400 \mathrm{~kg} / \mathrm{m}^{3}\right)$.

Sommerhalder (1972) measured shear and normal stresses for avalanches flowing over snowsheds in the Swiss Alps by installing mechanical devices over the breadth of gallery roofs. Over several winters, maximum values of shear and normal stresses were recorded; from these friction coefficients were computed. Friction coefficients ranged from 0.05 to 0.65 , with a mean of 0.27 for the breadth of the gallery.

Martinelli and others (1980) filmed a dry-slab avalanche over wet snow in the run-out zone and calculated the front velocity from time-distance curves. By regarding the avalanche as a rigid body they obtained friction coefficients that ranged from 0.13 to 0.32 .

\section{FIELD MEASUREMENTS}

Measurements of friction coefficients were carried out by allowing snow blocks to slide down the natural snow cover at Toikanbetsu, northern Hokkaido. In all, 27 runs were carried out on different types of dry snow. A typical block size used had the dimensions of $0.37 \mathrm{~m} \times 0.11 \mathrm{~m} \times$ $0.23 \mathrm{~m}$ and the average mass of blocks was $2.5 \mathrm{~kg}$. Each block was accelerated on a wooden chute, the bottom of which was covered with a very slippery plastic film, and then slid on to the natural snow surface. The motion of the blocks was filmed with a TV camera with $1 / 1000 \mathrm{~s}$ shutter speed at a rate of 60 frames/s. Density and hardness of the snow on the track were measured before and after each run, as was snow temperature. Blocks of both compact and granular snow were used.

All the results of these measurements are summarized in Table I. Runs $1 / 87$ to $8 / 87$ and $\mathrm{Al}$ to $\mathrm{A} 8$ were on the natural snow cover, mostly over new snow, and the blocks decelerated to a stop. Runs B0 to B5 took place on a fixed slope of $29^{\circ}$ after removal of successive snow layers down to $65 \mathrm{~cm}$ which gave rise to a wide range of snow conditions. Blocks on these runs decelerated, but did not come to a stop, within the run-out. Runs $\mathrm{C} 2$ to $\mathrm{C} 7$ were on a fixed slope of $42.5^{\circ}$ covered with new snow which was compacted artificially. The same track was used for all runs and the blocks accelerated down the slope. Three types of behaviour were clearly distinguished:

Type I: No ploughing, or only very little ploughing, occurred (14 runs).

Type II: Almost uniform ploughing occurred (five runs). and in some cases a slightly wave-like ploughing pattern was noted along the track.

Type III: Sinking occurred, the block ploughing deeper into the snow as it slid along the run-out (eight runs) (Fig. 1).

Type I behaviour occurred mainly over hard snow and type III behaviour was observed mainly over soft snow (Fig. 2 ). By ploughing we mean that the snow surface was lower after the passage of the block than it had been before, due mainly to compression under the sliding block after which

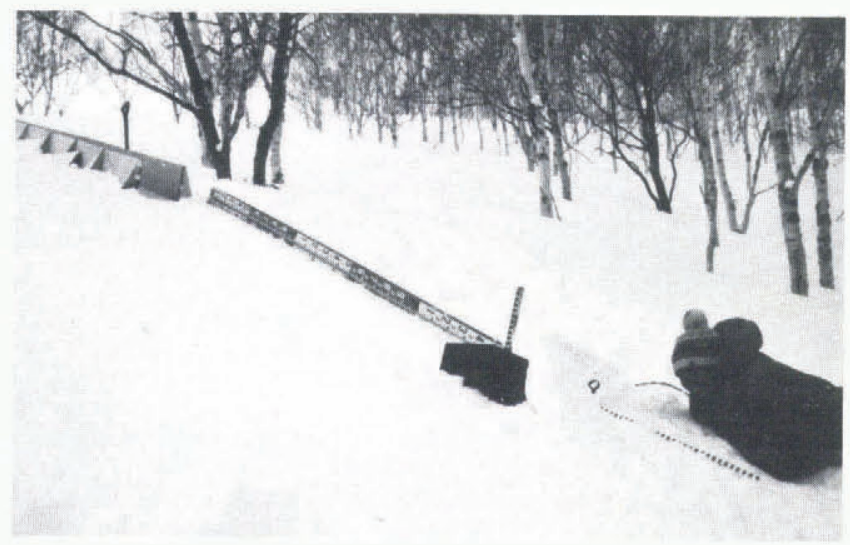

Fig. 1. General view of a typical sinking run (type III behaviour).

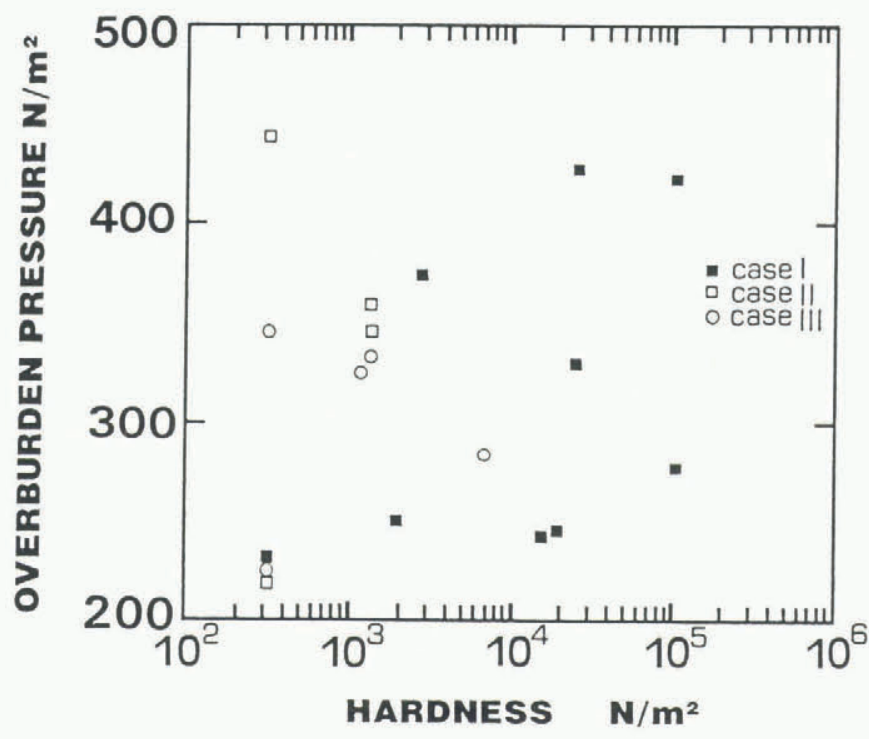

Fig. 2. Overburden pressure plotted against initial hardness on the track, showing the three different cases observed: no ploughing (type I behaviour), constant ploughing (type II behaviour), and sinking (type III behaviour).

shearing occurred. The amount of snow removed from the sides and the front of the block was small.

\section{ANALYSIS}

By analysing the video recording with an $X-Y$ coordinator, time-distance curves were obtained for each run. A fourth-degree time polynomial was fitted to the distance data, and expressions for velocity and acceleration were obtained separately for each time and distance. The time interval was usually $0.15 \mathrm{~s}$, which gave a smooth fit to the fourth-degree polynomial equation. The apparent friction coefficient, $\mu_{\mathrm{A}}$, is represented by

$$
\mu_{\mathrm{A}}=\frac{(g \sin \alpha-\mathrm{d} v / \mathrm{d} t)}{g \cos \alpha}
$$

where $\mathrm{d} v / \mathrm{d} t$ is the measured acceleration.

Measured values of $\mathrm{d} v / \mathrm{d} t$ may include errors due to air drag. This air drag, $F_{a}$, can be separated into pressure drag, $S_{\mathrm{p}}$, acting on the front area of the block with a drag coefficient, $C_{\mathrm{p}}$, and surface drag, $S_{\mathrm{s}}$, acting on the lateral surfaces with a different drag coefficient, $C_{S}$. Thus

$$
F_{\mathrm{a}}=0.5\left(C_{\mathrm{s}} S_{\mathrm{S}}+C_{\mathrm{p}} S_{\mathrm{p}}\right) \rho_{\mathrm{a}} v^{2}
$$

where $v$ is the velocity of the block and $\rho_{a}$ is an airdensity value of $1.3 \mathrm{~kg} / \mathrm{m}^{3}$.

The highest velocity for our runs was $7 \mathrm{~m} / \mathrm{s}$. Considering the kinematic viscosity of air, $v_{a}$ to be $1.47 \times 10^{-5} \mathrm{~m}^{2} / \mathrm{s}$ and a characteristic block dimension to be $0.3 \mathrm{~m}$ the Reynolds number, $\mathrm{Re}$, was calculated as $\mathrm{Re}=$ $1.4 \times 10^{5}$. Standard values of $C_{p}$ for this order of $R e$ are less than 1 , and $C_{\mathrm{S}}$ is less than 0.1. Adopting these as upper limits, the air drag for a velocity of $7 \mathrm{~m} / \mathrm{s}$ amounts to $1.2 \mathrm{~N}$, equivalent to $6.5 \%$ of the total drag, reducing the apparent friction coefficient in 0.08. Because we consider that this is an upper limit and that the errors involved in our estimate of $\mu_{\mathrm{A}}$ are in the order of 0.05 , correction for air drag is not considered to be necessary.

\section{Type I behaviour - no ploughing}

In these runs ploughing was negligible and $\mu_{\boldsymbol{A}}$ value obtained was almost constant through the whole run-out. We have assumed that only the dry friction is operating (Fig. 3). For runs $\mathrm{C} 2$ to $\mathrm{C} 7$ snow conditions were identical. When $\mu_{\mathrm{A}}$ was plotted against $S / m \cos \alpha$ with $\mu_{\mathrm{C}}=0.58$ and $a=2.2 \mathrm{~kg} / \mathrm{m}^{2}$ (Fig. 4), a linear fit was obtained, as would be expected from Equation (6). If we consider all the 14 runs including each variety of snow conditions, a mean Coulomb friction value of 0.62 , and a mean adhesion 


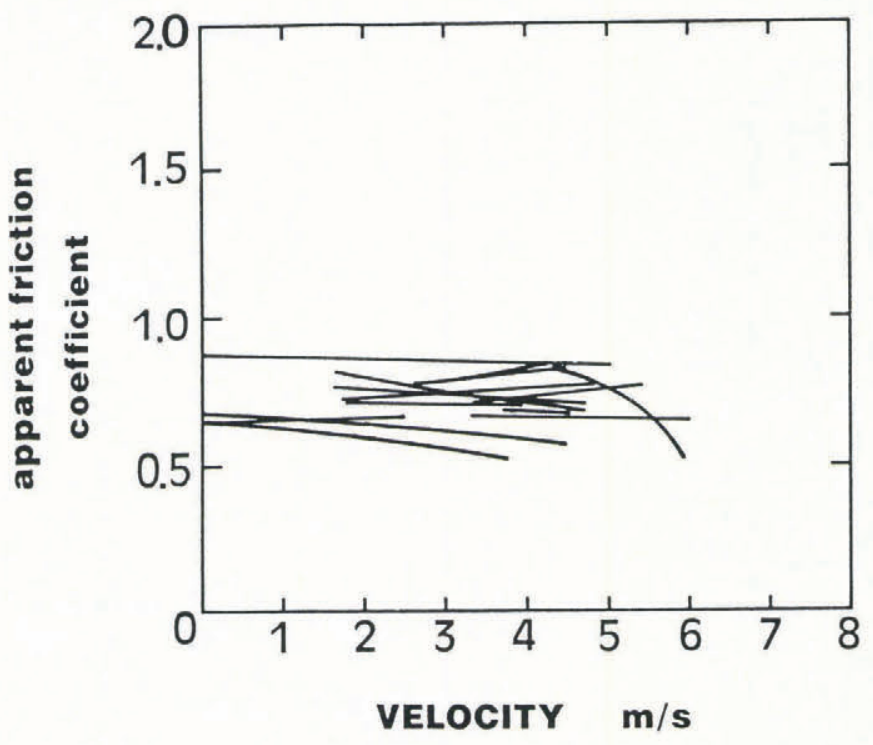

Fig. 3. Apparent friction coefficient plotted against velocity for the non-ploughing runs (type I behaviour).

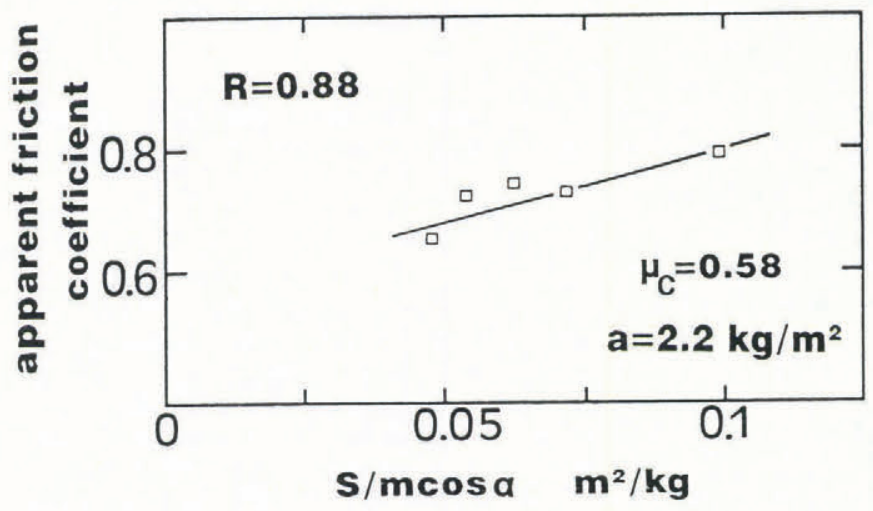

Fig. 4. Determination of adhesion coefficient, $a$, and Coulomb friction coefficient, $\mu_{\mathrm{c}}$, for run C. $R$ is the correlation coefficient. $\mu_{c}$ was obtained by extrapolating the line to the ordinate axis and a corresponds to the slope.

coefficient value of $2.1 \mathrm{~kg} / \mathrm{m}^{2}$, are obtained. The adhesion value is rather similar in magnitude to that obtained by Inaho. The physical origin of the adhesion is at present not clear, but it should be noted that the value of $a g$ is roughly $20 \mathrm{~N} / \mathrm{m}^{2}$, which is between two and four orders of magnitude smaller than the shearing strength of coherent snow.

\section{Type II behaviour - constant ploughing}

In these runs a shear layer developed between the snow surfaces along the run-out. Figure 5 shows that $\mu_{\mathrm{A}}$ increased almost linearly with velocity, suggesting a viscous resistance. Thus, $\mu_{A}$ can be separated into a dry-friction coefficient $(\mu)$ and a linear velocity term which correspond to the terms $A+B v$ of Equation (1). Linear fits yielded $\mu_{\mathrm{A}}$ values of between 0.57 and 0.86 at zero velocity (Table II); these values lie in the range of the dry-friction coefficients found in the non-ploughing cases. Viscous coefficients per unit area, $B / S$, ranged from $11 \mathrm{~N} \mathrm{~s} / \mathrm{m}^{3}$ to $75 \mathrm{~N} \mathrm{~s} / \mathrm{m}^{3}$, and are smaller than the value of $475 \mathrm{~N} \mathrm{~s} / \mathrm{m}^{3}$ recorded by Bucher and Roch. This is readily explained by considering that in our experiments snow had a higher degree of fluidization and therefore a lower viscosity, and also a better developed shear layer than that of the snow previously studied. Lang and Dent (1983) dragged sled runners coated with sand over hard sintered snow and found that shear stress increased linearly with velocity, with $\mathrm{B} / \mathrm{S}$ values ranging from $132 \mathrm{~N} \mathrm{~s} / \mathrm{m}^{3}$ to $197 \mathrm{~N} \mathrm{~s} / \mathrm{m}^{3}$. The linear fits obtained by Bucher and Roch (1946) and Lang and Dent (1983) are shown in Figure 5. Values of all viscous coefficients are summarized in Table II.

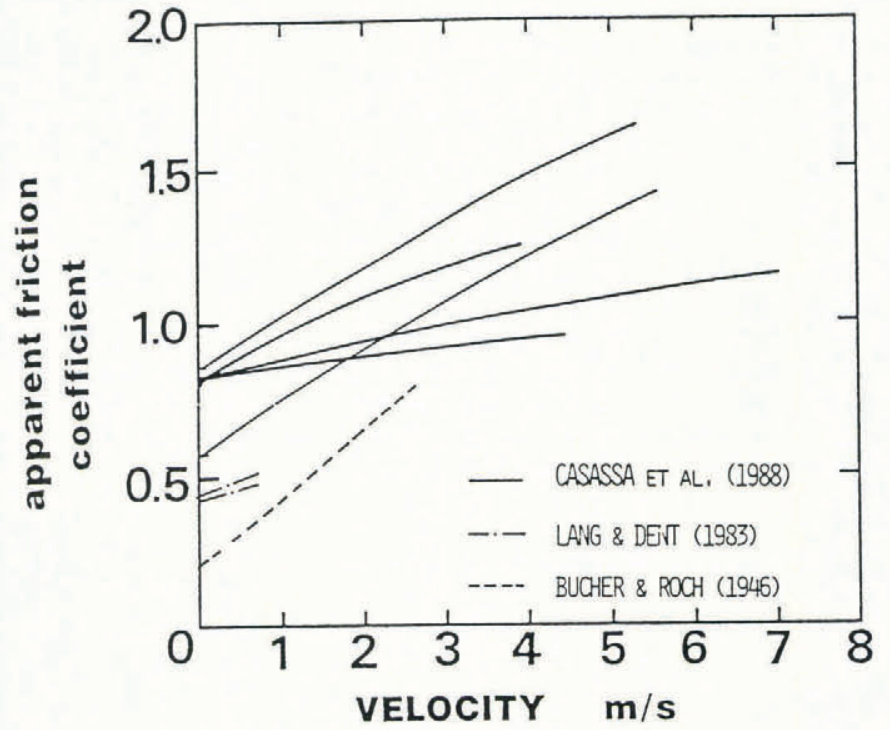

Fig. 5. Apparent friction coefficient plotted against velocity for the constant ploughing runs (type II behaviour).

Assuming $\delta$ to be one-third of the average ploughing thickness, values of kinematic viscosity were calculated to be in the order of $4 \times 10^{-4}$ to $3 \times 10^{-3} \mathrm{~m}^{2} / \mathrm{s}$. These values are in agreement with the data from Bucher and Roch (1946) and from Lang and Dent (1983). Although the above-estimated kinematic viscosity is one or two orders of magnitude greater than the experimental values obtained by Nishimura and Maeno (1988) for snow particles of $0.5 \mathrm{~mm}$ diameter, it agrees fairly well with the $1 \times 10^{-3}$ to $9 \times 10^{-3} \mathrm{~m}^{2} / \mathrm{s}$ obtained by Maeno and others (1980) for fluidized snow of $2 \mathrm{~mm}$ particle diameter.

\section{Type III behaviour - sinking}

As shown in Figure 6, $\mu_{A}$ values for type III behaviour are greater than unity and decrease with velocity, in contrast with those of type II, implying that the ploughing effect is very important in causing sinking. The force due to this ploughing effect has been estimated by use of a crude model of plastic deformation. From blockvelocity data and density measurements made before and after each run, extremely high values were obtained, sometimes exceeding three times the total drag. In fact, ploughing is a complicated effect which depends strongly on the mechanical properties of snow, and to model it correctly we must also consider snow shearing and compression.

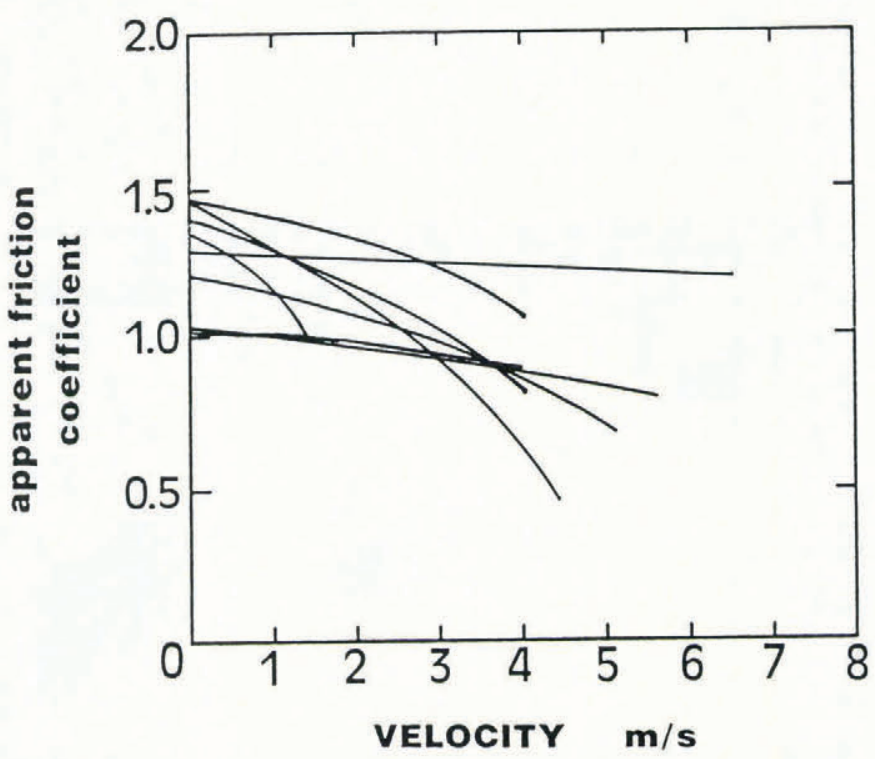

Fig. 6. Apparent friction coefficient plotted against velocity for the sinking runs (type III behaviour). 
TABLE I

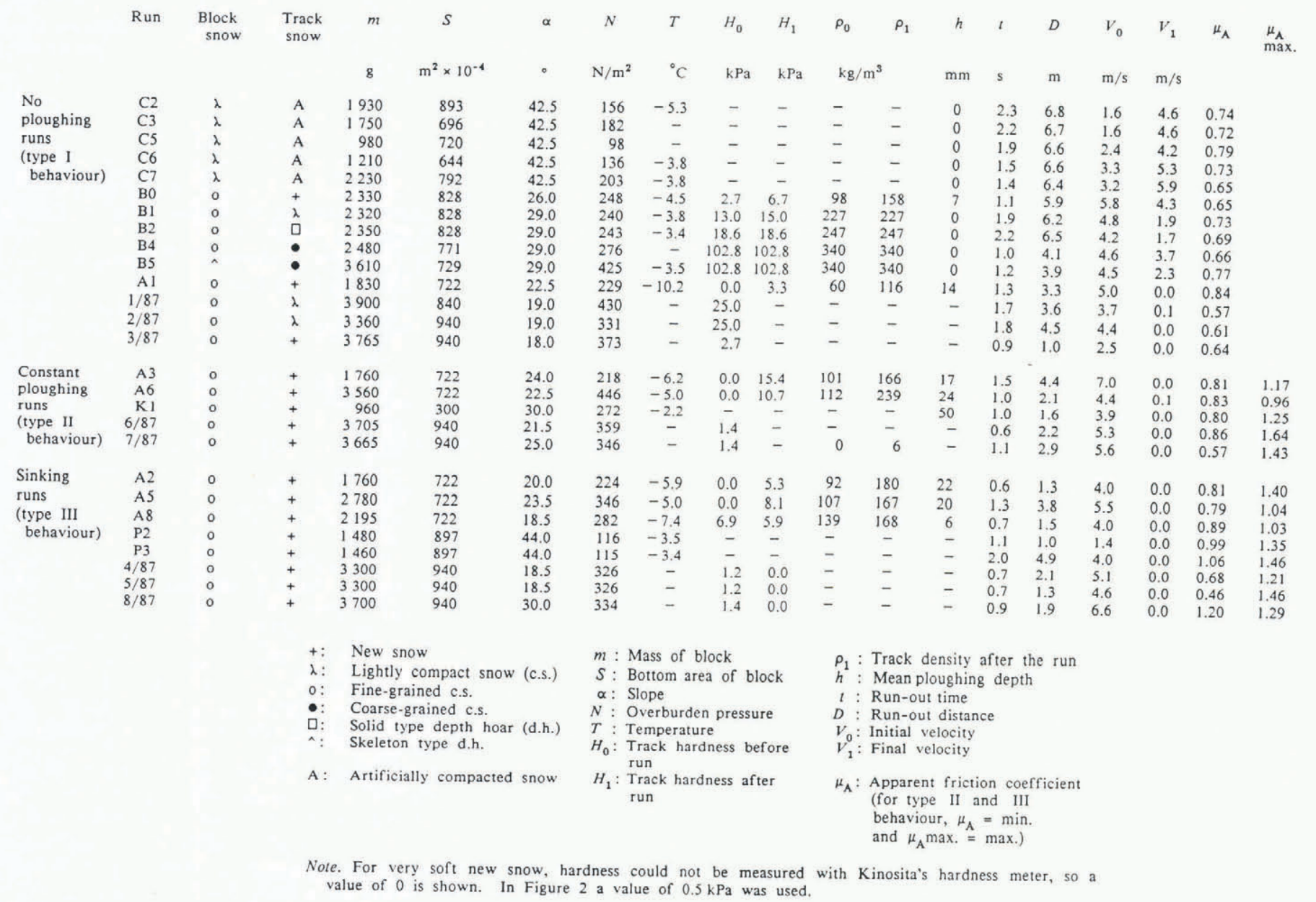

TABLE II. VISCOUS COEFFICIENTS FOR CONSTANT PLOUGHING RUNS (Column headings as indicated in the text.)

$\begin{array}{lcccccccc}\text { Run } & \rho & \mu & B & B / S & N & \mathrm{v} / \delta & \delta & v \\ & \mathrm{~kg} / \mathrm{m}^{3} & & \mathrm{~N} \mathrm{~s} / \mathrm{m} & \mathrm{N} \mathrm{s} / \mathrm{m}^{3} & \mathrm{~N} / \mathrm{m}^{2} & \mathrm{~m} / \mathrm{s} & \mathrm{mm} & \mathrm{m}^{2} / \mathrm{s} \\ \mathrm{A} 3 & 166^{(1)} & 0.81 & 0.8 & 11 & 218 & 0.067 & 6 & 4.0 \times 10^{-4} \\ \mathrm{~A} 6 & 239^{(1)} & 0.83 & 1.1 & 15 & 446 & 0.064 & 8 & 5.1 \times 10^{-4} \\ \mathrm{~K} 1 & 250^{(2)} & 0.80 & 1.1 & 37 & 272 & 0.147 & 17 & 2.5 \times 10^{-3} \\ 6 / 87 & 250^{(2)} & 0.86 & 8.0 & 85 & 359 & 0.340 & 10^{(2)} & 3.4 \times 10^{-3} \\ 7 / 87 & 250^{(2)} & 0.57 & 7.0 & 75 & 346 & 0.300 & 10^{(2)} & 3.0 \times 10^{-3} \\ \begin{array}{l}\text { Bucher and } \\ \text { Roch }\end{array} & 300^{(3)} & 0.23 & - & 475^{(3)} & 2156 & 1.580 & 2^{(3)} & 3.0 \times 10^{-3} \\ \begin{array}{l}\text { Lang and } \\ \text { Dent }\end{array} & 400 & 0.44 & - & 131 & 1180 & 0.320 & & \left\{\begin{array}{l}2.5 \times 10^{-3} \\ \text { to } 5 \times 10^{-4}\end{array}\right\} \\ \begin{array}{l}\text { Lang and } \\ \text { Dent }\end{array} & 400 & 0.42 & - & 197 & 2360 & 0.490 & & \end{array}$

(1) The shear layer snow density was estimated to be the same as the track density after the run.

(2) Estimated values.

(3) Estimated by Lang and Dent (1982).

(4) Computed from direct measurements of velocity and shear-layer thickness. 


\section{CONCLUDING REMARKS}

The upper value for the dry-friction coefficient used in avalanche dynamics has been taken to be 0.5 (Schaerer, 1975), and typical values range between 0.1 and 0.4. The friction coefficient depends strongly on snow fluidization. At low densities and/or high avalanche speeds it seems reasonable to suggest low values for $\mu$, perhaps as low as 0.1 in the case of a fully developed powder avalanche. In fact Sommerhalder (1972) found an average value for $\mu$ of 0.27 for flowing avalanches, and Martinelli and others (1980) found an average value of 0.37 in the run-out for a slab avalanche. In contrast, our values for the dry-friction coefficient obtained for snow blocks running on a snow surface are much higher, ranging from 0.57 to 0.84 . By averaging dry-friction coefficients reported in previous snow-block experiments, we obtain values of 0.58 (Inaho, 1941), 0.47 (Bucher and Roch, 1946), and 0.70 (Japan National Railways, 1961). These values agree well with our results. Our preliminary measurements have confirmed the high friction between isolated snow blocks and smooth snow cover; the situation is considered to be similar to the bed friction of a slab avalanche near its starting zone. In loose-snow avalanches the high degrees of fluidization attained may lead to the low values of friction frequently found in practice.

In our laboratory more detailed measurements are under way in a cold room, as are experiments to generate a torque in a rotating snow block in contact with a loaded snow surface. The latter are being carried out in order to determine more precisely the value of the dry-friction coefficient and the contribution of Coulomb forces, adhesion, viscosity, and other factors to the frictional resistance. The influence of temperature, overburden pressure, and velocity will also be studied.

\section{ACKNOWLEDGEMENTS}

The authors are indebted to the following individuals, all of the Institute of Low Temperature Science, Hokkaido
University, for much help in the field work: R. Naruse, K. Nishimura, S. Murakami, K. Kosugi, and K. Akagi; and also to R. Nitta of the Forestry and Forest Products Research Institute, Japan, and W. Good and B. Salm of the Swiss Federal Institute for Snow and Avalanche Research for providing valuable information.

\section{REFERENCES}

Bucher, E. and A. Roch. 1946. Reibungs- und Packungswiderstande bei raschen Schneebewegungen. Eidg. Inst. Schnee Lawinenforsch. Rapp.

Inaho, Y. 1941. Angle of kinetic friction of snow. J. Jpn. Soc. Snow Ice, 3, 303-307. [In Japanese.]

Japan National Railways. 1961. Kinetic friction and sliding velocity of avalanches. J. Jpn. Soc. Snow Ice, 23(5), 1-4. [In Japanese.]

Lang, T.E. and J.D. Dent. 1982. Review of surface friction, surface resistance, and flow of snow. Rev. Geophys. Space Phys., 20(1), 21-37.

Lang, T.E. and J.D. Dent. 1983. Basal surface-layer properties in flowing snow. Ann. Glaciol., 4, 158-162.

Maeno, N., K. Nishimura, and Y. Kaneda. 1980. $\mathrm{Viscosity}$ and heat transfer in fluidized snow. J. Glaciol., 26(94), 263-274.

Martinelli, M., jr, T.E. Lang, and A.I. Mears. 1980. Calculations of avalanche friction coefficients from field data. J. Glaciol., 26(94), 109-119.

Nishimura, K. and N. Maeno. 1989. Contribution of viscous forces to avalanche dynamics. Ann Glaciol., 13, 202-206.

Salm, B. 1966. Contribution to avalanche dynamics. International Association of Scientific Hydrology Publication 69 (Symposium at Davos 1965 - Avalanche and Physics of Snow), 199-214.

Sommerhalder, E. 1972. Albenkverbau, in Lawinenschutz in der Schweiz-Bundnerwald [Avalanche protection in Switzerland]. Genossenschaft der Bundnerischen Holzproduzentan, 9, 155-169. [English translation: Washington, DC, U.S. Department of Agriculture. Forest Service. (General Technical Report Rm-9, 1975.).] 